\title{
Hepatitis C Rapid Point-of-Care Testing and Laboratory- based Non-invasive Assessment of Liver Fibrosis among Drug Abusers: An Experience from Iran
}

\author{
Mohammad Reza Hedayati-Moghaddam, MD ${ }^{1,2^{*}}$; Hossein Soltanian, BSc ${ }^{1,2}$; Majid Danaee, PhD ${ }^{2,3}$; Seyed Ahmad Vahedi, MSc ${ }^{4}$ \\ 'Blood Borne Infections Research Center, Academic Center for Education, Culture \& Research (ACECR), Razavi Khorasan Branch, Mashhad, \\ Iran \\ ${ }^{2}$ Razavi Khorasan Hepatitis Association (NGO), Mashhad, Iran \\ ${ }^{3}$ Social Sciences Research Group, Research Institute of Tourism, Academic Center for Education, Culture \& Research (ACECR), Razavi Khorasan \\ Branch, Mashhad, Iran \\ ${ }^{4}$ Academic Center for Education, Culture \& Research (ACECR), Razavi Khorasan Branch, Mashhad, Iran
}

\begin{abstract}
Background: People who use drugs, particularly injection drug users (IDUs) are known as the major source of hepatitis $C$ virus (HCV) infection. This study was performed to determine the prevalence of HCV infection using rapid point-of-care testing and to assess liver fibrosis by non-invasive lab tests among addict populations of Mashhad, Iran.

Methods: In this cross-sectional study, drug users who referred to drug treatment and harm reduction centers of Mashhad were enrolled during March and December 2019. A rapid test kit was used to assess the presence of anti-HCV antibodies and a realtime PCR was performed to confirm the infection. The AST-platelet ratio index (APRI) and fibrosis-4 (FIB-4) score were used to investigate liver fibrosis in patients with positive HCV RNA. A $P$ value $<0.05$ was considered as significant.

Results: A total of 390 drug users aged 15-74 years were assessed. Sixty-four individuals showed positive results for anti-HCV (16.4\%), of whom 58 blood samples were available for PCR test. The viremic rate among the latter group was calculated at $84.5 \%$ (49/58); the total viremia prevalence was $12.8 \%$ (49/384). Multivariate analysis revealed that being single $(P=0.040)$ or divorced/ widow $(P=0.011)$ and history of drug injection $(P<0.001)$ and tattoos $(P=0.021)$ were significantly associated with current $\mathrm{HCV}$ infection. Using APRI and FIB-4 indices, significant liver fibrosis was identified in $14.3 \%$ and $18.4 \%$ of cases, respectively.

Conclusion: HCV infection screening using rapid tests and examining liver fibrosis by non-invasive lab tests appear to be practicable and useful among poor populations in settings such as drug treatment centers.

Keywords: Drug users, Hepatitis C, Iran, Liver fibrosis, Point-of-care testing, Prevalence

Cite this article as: Hedayati-Moghaddam MR, Soltanian H, Danaee M, Vahedi SA. Hepatitis C rapid point-of-care testing and laboratory-based non-invasive assessment of liver fibrosis among drug abusers: an experience from Iran. Arch Iran Med. 2021;24(2):94-100. doi: 10.34172/aim.2021.14.
\end{abstract}

Received: May 12, 2020, Accepted: October 21, 2020, ePublished: February 1, 2021

\section{Introduction}

Hepatitis C virus (HCV) infection is a significant health issue in the world. Globally, 71 million persons are chronically infected with $\mathrm{HCV}$, corresponding to a prevalence of $1.0 \% .{ }^{1}$ According to an estimation by the World Health Organization (WHO), nearly 400000 people died in 2016 from hepatitis C, mainly from liver cirrhosis and hepatocellular carcinoma. ${ }^{2}$ With an overall prevalence of $0.6 \%$ for antibodies specific to HCV (anti$\mathrm{HCV}$ ) seropositivity and $0.4 \%$ for $\mathrm{HCV}$ viremia in the general population, Iran is considered an area with low frequency of $\mathrm{HCV}$ infection. ${ }^{3}$ However, some authors have predicted a 3-4-fold increase in the number of patients with liver disease and its related death by 2030 , assuming the current $\mathrm{HCV}$ diagnosis/treatment settings in the country. ${ }^{4,5}$

Drug users, especially those who inject drugs, are a high- risk population for infection with parenterally transmitted pathogens, including viral hepatitis $\mathrm{B}$ and $\mathrm{C}$ viruses. ${ }^{6}$ Considering an average $\mathrm{HCV}$ prevalence of $67 \%$ among injection drug users (IDUs), it is globally estimated that nearly 10 million IDUs have serological evidence of HCV infection, although the rate of prevalence varies greatly from $10 \%$ to $97 \% .^{7}$ Estimates by some systematic reviews from Iran showed an HCV prevalence of 14.5\%-16.2\% among non-IDUs and 41.3\%-52.6\% among IDUs. ${ }^{8-10}$ Based on a systematic review of surveys including 13,821 drug users outside of prison in Iran, the total HCV prevalence was 45\% (95\% CI 37\%-54\%) among IDUs and $8 \%(95 \%$ CI 4\%-13\%) among drug users without an injection history. ${ }^{11}$ As a key population at high risk of HCV infection, IDUs account for a large proportion of the virus spread in Iran..$^{5}$ A modelling study showed an at least $10 \%$ rise in $\mathrm{HCV}$ prevalence since 2007 due to 
infections among IDUs in this country. ${ }^{1}$

$\mathrm{HCV}$ diagnosis and treatment have been projected as important steps to achieve the global goal of viral hepatitis elimination by $2030 .^{12}$ At the point of care, using rapid diagnostic tests (RDTs) is strongly recommended to enhance linkage to care and treatment among hard-toaccess groups, even in high-income countries. ${ }^{13}$ Besides, in poor populations with $\mathrm{HCV}$ infection, it is recommended that low-cost and more feasible laboratory-based testing such as the AST-platelet ratio index (APRI) and fibrosis-4 score (FIB-4) should be used for the pre-treatment evaluation of liver fibrosis rather than other high-priced invasive or non-invasive methods such as liver biopsy and elastography. ${ }^{13}$

Mashhad, the capital city of the Razavi Khorasan province in northeastern Iran, is the second-largest city of the country. The overall prevalence of $\mathrm{HCV}$ infection among the general population of Mashhad was reported as low as $0.42 \%(95 \% \mathrm{CI}: 0.17 \%-0.87 \%) .{ }^{14}$ However, the rate of this infection among imprisoned drug users of this city was reported as high as $34.7 \% .{ }^{15}$ The present study was performed to determine the prevalence of HCV infection among drug users in Mashhad, Iran using rapid test kits and to assess liver fibrosis using non-invasive lab tests.

\section{Materials and Methods}

In this cross-sectional study, drug users who referred to drug treatment and harm reduction centers in Mashhad were recruited from March to December 2019. According to the Anti-Narcotics Law of Iran passed in 2010, all addict people are permitted to refer to voluntary legal outpatient or residential opioid treatment and harm reduction centers. However, street drug users who refuse treatment in voluntary centers are transferred to mandatory centers by the police for rehabilitation and treatment. ${ }^{16}$ We selected four centers, including two mandatory and two voluntary centers based on a nonrandom sampling method. By assuming a prevalence rate of $20 \%$, confidence interval (CI) of $95 \%$, and precision rate of $4 \%$, we needed a minimum of 385 cases to estimate the population prevalence with good precision.

After clarifying the aim of the study and obtaining written informed consents, the participants were asked for demographic features, medical histories and risky behaviors associated with HCV infection. By a fingerstick procedure using a lancet, $10 \mu \mathrm{L}$ of capillary whole blood was collected and transferred to a rapid test device using a disposable micropipette. After applying four drops of diluent, the presence of anti-HCV was qualitatively assessed at 5-20 minutes based on the instruction manual of the kit (SD Bioline HCV, Standard Diagnostics Inc., South Korea). The letters "T" and " $C$ " on the surface of the device represent test and control line, respectively, which will become visible after applying the specimen. The tests were carried out by the lab technician members of the research team or by well-trained healthcare worker of the centers. With $99.3 \%$ sensitivity and $98.1 \%$ specificity, the positive cases were considered for additional testing by real-time polymerase chain reaction (PCR) assay for detection of HCV RNA as well as hematology and biochemistry tests for assessment of liver fibrosis. A venous blood sample was drawn and transported to the Central Lab of the Academic Center for Education, Culture \& Research (ACECR), Razavi Khorasan Branch (Mashhad, Iran). Hepatitis $C$ viral RNA was extracted from the serum samples (DynaBio Viral Nucleic Acid Extraction Mini Kit, Takapouzist, Iran) and real-time PCR test was performed via a Rotor-Gene 6000 (Q) device with a minimum limit of $50 \mathrm{IU} / \mathrm{mL}$ (Novin Gene HCV Detection and Quantitation kit, AmitisGen, Iran) according to the manufacturers' guidelines.

The blood platelet count, prothrombin time (PT), and serum levels of alanine transaminase (ALT), aspartate transaminase (AST), alkaline phosphatase (ALP), bilirubin, and albumin were assessed in patients with active HCV replication. The APRI and FIB-4 were applied for measurement of the severity of liver fibrosis. The APRI index was calculated as follow: [(AST (IU/L)/ $40) \times 100] /$ platelet count $\left(10^{\wedge} 9 / \mathrm{L}\right) \cdot{ }^{17}$ An index less than 0.5 can be used with $82 \%$ sensitivity to exclude significant liver fibrosis (METAVIR stage $\geq 2$ ) and a score greater than 1.5 would have $92 \%$ specificity for predicting fibrosis. The FIB-4 score was calculated as follows: age (years.) $\times$ AST $(\mathrm{IU} / \mathrm{L}) /$ platelet count $\left(10^{\wedge} 9 / \mathrm{L}\right) \times[$ ALT $(\mathrm{IU} / \mathrm{L}) \wedge 1 / 2] .{ }^{17} \mathrm{~A}$ score of less than 1.45 can be applied with $89 \%$ sensitivity to exclude significant hepatic fibrosis and a score greater than 3.25 would have $74 \%$ specificity for predicting fibrosis. Data were analyzed by chi-square and Fisher exact tests, if needed, using SPSS version 19.0 (IBM Corp., Armonk, NY, USA). In addition, a multivariate analysis by logistic regression was applied to analyze the factors related to HCV RNA positivity. A $P$ value $<0.05$ was considered as significant. Odds ratios (ORs) with 95\% CI were also calculated in both bivariate and multivariate analyses.

\section{Results}

A total of 390 drug users, including 293 men and 97 women with a mean age of $39.0 \pm 10.4$ (range 15-74) years were assessed. A history of drug injection, tattoos, and imprisonment was reported among 19.7\% (72/366), $41.1 \%$ (159/387), and 62.9\% (244/388) of responders, respectively. Moreover, 30 of 71 individuals (42.3\%) with a history of drug injection reported sharing a syringe or needle in the past. From 51 persons (13.1\%) with a history of transfusion, only 5 subjects were transfused before 1996, when nation-wide HCV screening was started in the blood centers of Iran.

Sixty-four drug users showed reactive bands and were considered positive for anti-HCV (16.4\%, 95\% CI 
12.9\%-20.5\%). Among these 64 cases, we were able to take whole blood samples from 58 cases for performing the real-time PCR test, of whom 49 patients (84.5\%) had detectable HCV RNA in their serum, corresponding to a total prevalence of $12.8 \%$ (49/384, 95\% CI 9.6\%$16.5 \%)$ for viremic infection. The highest prevalence was observed among IDUs (42.6\%, 95\% CI: 30.7\%-55.2\%). $\mathrm{HCV}$ infection was more frequent in men (14.6\%,
95\% CI: $10.8 \%-19.3 \%)$ than women $(7.2 \%, 95 \%$ CI: $3.0 \%-14.3 \%)$, however, the difference was not statistically significant $(P=0.058)$. As Table 1 shows, the infection rate was significantly higher in older $(P=0.001)$ and unmarried participants $(P=0.037)$, and those with a history of drug injection $(P<0.0001)$, tattoos $(P<0.0001)$, imprisonment $(P<0.0001)$, blood transfusion $(P=0.016)$, and pre- or extra-marital sexual contact $(P=0.026)$. Furthermore,

Table 1. Demographic Features, Medical Histories and Risky Behaviors Associated with HCV Infection in Drug Users of Mashhad, Iran

\begin{tabular}{|c|c|c|c|c|c|}
\hline Variables & HCV-Positive, No. (\%) & HCV-Negative, No. (\%) & Odds Ratio & $95 \% \mathrm{Cl}$ & $P$ Value $^{\mathrm{a}}$ \\
\hline \multicolumn{6}{|l|}{ Treatment center } \\
\hline A & $16(14.4)$ & $95(85.6)$ & \multirow{4}{*}{-} & \multirow{4}{*}{ - } & \multirow{4}{*}{0.278} \\
\hline B & $4(12.1)$ & $29(87.9)$ & & & \\
\hline $\mathrm{C}$ & $22(15.4)$ & $121(84.6)$ & & & \\
\hline $\mathrm{D}$ & $7(7.2)$ & $90(92.8)$ & & & \\
\hline \multicolumn{6}{|l|}{ Type of treatment center } \\
\hline Voluntary & $20(13.9)$ & $124(86.1)$ & \multirow{2}{*}{0.85} & \multirow{2}{*}{$0.46-9.57$} & \multirow{2}{*}{0.608} \\
\hline Obligatory & $29(12.1)$ & $211(87.9)$ & & & \\
\hline \multicolumn{6}{|l|}{ Age $(y)$} \\
\hline$<30$ & $0(0)$ & $68(100)$ & \multirow{3}{*}{ - } & \multirow{3}{*}{ - } & \multirow{3}{*}{0.001} \\
\hline $30-49$ & $35(14.2)$ & $211(85.8)$ & & & \\
\hline$\geq 50$ & $14(20.0)$ & $56(80.0)$ & & & \\
\hline \multicolumn{6}{|l|}{ Gender } \\
\hline Men & $42(14.6)$ & $245(85.4)$ & \multirow{2}{*}{2.20} & \multirow{2}{*}{$0.96-5.08$} & \multirow{2}{*}{0.058} \\
\hline Women & $7(7.2)$ & $90(92.8)$ & & & \\
\hline \multicolumn{6}{|l|}{ Marital status } \\
\hline Single & $16(13.9)$ & $99(86.1)$ & \multirow{3}{*}{ - } & \multirow{3}{*}{ - } & \multirow{3}{*}{0.037} \\
\hline Married & $14(8.1)$ & $158(91.9)$ & & & \\
\hline Divorced/Widowed & $18(18.8)$ & $78(81.3)$ & & & \\
\hline \multicolumn{6}{|l|}{ Education } \\
\hline Illiterate & $4(7.7)$ & $48(92.3)$ & \multirow{4}{*}{ - } & & \\
\hline Elementary school & $18(13.7)$ & $113(86.3)$ & & & 0.437 \\
\hline Secondary/high school & $26(14.4)$ & $154(85.6)$ & & - & 0. \\
\hline Academic education & $1(5.3)$ & $18(94.7)$ & & & \\
\hline Employment & & & & & \\
\hline Employed & $20(10.0)$ & $181(90.0)$ & 058 & ( $32-107$ & 0080 \\
\hline Unemployed & $29(15.9)$ & $153(84.1)$ & 0.50 & $0.32-1.07$ & 0.000 \\
\hline History of blood transfusi & & & & & \\
\hline Yes & $11(22.9)$ & $37(77.1)$ & 247 & $116-528$ & 0016 \\
\hline No & $35(10.7)$ & $291(89.3)$ & 2.47 & $1.16-5.28$ & 0.016 \\
\hline History of tattooing & & & & & \\
\hline Yes & $33(21.2)$ & $123(78.8)$ & 352 & $186-666$ & $<000001$ \\
\hline No & $16(7.1)$ & $210(92.9)$ & 3.52 & $1.86-6.66$ & $<0.0001$ \\
\hline History of drug injection & & & & & \\
\hline Yes & $29(42.6)$ & $39(57.4)$ & 1147 & $579-2244$ & $<00001$ \\
\hline No & $18(6.1)$ & $276(93.9)$ & 11.47 & $5.13-22.44$ & -0.0001 \\
\hline History of imprisonment & & & & & \\
\hline Yes & $43(18.0)$ & $196(82.0)$ & 505 & $209-1218$ & $<0,0001$ \\
\hline No & $6(4.2)$ & $138(95.8)$ & 3.03 & $2.09-12.10$ & $<0.0001$ \\
\hline History of sexual contact & & & & & \\
\hline Yes & $26(17.7)$ & $121(82.3)$ & 197 & $108-361$ & 0.026 \\
\hline No & $23(9.8)$ & $211(90.2)$ & & & \\
\hline History of drug use in spc & & & & & \\
\hline Yes & $9(13.2)$ & $59(86.8)$ & 124 & $0.52-297$ & 0.629 \\
\hline No & $16(11.0)$ & $130(89.0)$ & 1.24 & $0.52-2.97$ & 0.023 \\
\hline History of spouse impriso & & & & & \\
\hline Yes & $7(12.7)$ & $48(87.3)$ & 115 & $045-292$ & 0768 \\
\hline No & $18(11.2)$ & $142(88.8)$ & 1.15 & $0.45-2.92$ & 0.768 \\
\hline
\end{tabular}

${ }^{\mathrm{a} C h i-s q u r e ~ t e s t . ~}$ 
the rates of HCV infection among IDUs with a history of needle sharing $(51.7 \%, \mathrm{n}=15)$, imprisonment $(45.9 \%, \mathrm{n}$ $=28)$, and tattoos $(45.0 \%, \mathrm{n}=18)$ were significantly higher than non-IDUs with no history of the abovementioned risky behaviors/settings $(9.6 \%, \mathrm{n}=32,6.3 \%, \mathrm{n}=19$, and $9.1 \%, \mathrm{n}=29$, respectively, $P<0.0001$ for all). On the other hand, no association was observed between HCV infection and the treatment center, participants' education level and employment status, and history of drug use or incarceration for the responder's spouse $(P>0.05)$. Multivariate analysis revealed that being single $(P=0.040$, OR: 2.76) and divorced or widowed ( $P=0.011$, OR: 3.38$)$ and a history of drug injection $(P<0.001$, OR: 6.86) and tattoos $(P=0.021$, OR: 2.64$)$ were significantly associated with the current HCV infection (Table 2).

Table 3 indicates the results of hematology and biochemistry tests in population with active $\mathrm{HCV}$ infection. Based on the APRI score, the probability of significant liver fibrosis (index $>1.5$ ) was reported for seven patients including six men and one woman $(14.3 \%, 95 \%$ CI: $10.8 \%-19.3 \%)$. On the other hand, regarding FIB4 , the probability of significant fibrosis (score $>3.25$ ) was suggested for nine patients including eight men and one woman (18.4\%, 95\% CI: $10.8 \%-19.3 \%)$. Among the

Table 2. Logistic Regression Analysis of the Association of HCV Infection with Selected Variables in Drug Users of Mashhad, Iran

\begin{tabular}{llcc}
\hline Variables & $\boldsymbol{P}$ Value & Odds Ratio & $\mathbf{9 5 \%} \mathbf{C l}$ \\
\hline Age (y) & & - & - \\
$30-49$ & 0.997 & - & - \\
$\quad$ 250 & 0.997 & & \\
Marital status & & 2.76 & $1.05-7.27$ \\
$\quad$ Single & 0.040 & 3.38 & $1.33-8.58$ \\
$\quad$ Divorced/Widowed & 0.011 & 2.06 & $0.82-5.22$ \\
\hline Blood transfusion & 0.125 & 2.64 & $1.16-6.01$ \\
\hline Tattooing & 0.021 & 6.86 & $3.04-15.47$ \\
\hline Drug injection & $<0.001$ & 1.42 & $0.50-3.99$ \\
\hline Imprisonment & 0.511 & 1.21 & $0.54-2.68$ \\
\hline Sexual contact & 0.646 & & \\
\hline Cl, confidence interval. & & & \\
\hline
\end{tabular}

Table 3. Results of Hematology and Biochemistry Tests in Drug Users with Active HCV Infection in Mashhad, Iran

\begin{tabular}{lccc}
\hline Test & Mean \pm SD $^{\text {a }}$ & Min, Max & Abnormal Value; No. (\%) \\
\hline Blood platelet (/L) & $210.5 \pm 101.6$ & 29,419 & $<150 ; 11(22.4 \%)$ \\
PT (s) & $12.5 \pm 1.1$ & $11.0,17.2$ & $>13.0 ; 11(23.9 \%)$ \\
INR & $1.1 \pm 0.1$ & $0.9,1.8$ & $>1.1 ; 11(23.9 \%)$ \\
ALT (U/L) & $45.7 \pm 27.6$ & 10,125 & $>40 ; 21(42.9 \%)$ \\
AST (U/L) & $35.0(29.0,46.5)$ & 14,110 & $>40 ; 14(28.6 \%)$ \\
ALP (U/L) & $178.1 \pm 50.9$ & 90,330 & $>306 ; 1(2.0 \%)$ \\
Total bilirubin (mg/dL) & $0.4(0.2,0.6)$ & $0.1,1.2$ & $>1.2 ; 1(2.0 \%)$ \\
Albumin (g/dL) & $4.1(3.9,4.2)$ & $3.1,4.6$ & $>3.6 ; 5(10.2 \%)$ \\
APRI & $0.41(0.31,0.73)$ & $0.12,4.74$ & $>1.5 ; 7(14.3 \%)$ \\
FIB-4 & $1.28(0.72,1.94)$ & $0.43,15.83$ & $>3.25 ; 9(18.4 \%)$ \\
\hline
\end{tabular}

PT, protrombin time; ALT, alanine transaminase; AST, aspartate transaminase; ALP, alkaline phosphatase; APRI, AST-platelet ratio index; FIB-4, fibrosis-4 score; INR, International normalized ratio; Min, Minimum; Max, Maximum; n, Number; SD, Standard deviation.

${ }^{a}$ Median (and interquartile ranges) were calculated for description of variables with skewed distribution including AST, total bilirubin, albumin, APRI, and FIB-4. latter group, all were 44 years and older, and seven persons had an APRI score $>1.5$, too. Based on FIB-4, IDUs were more likely to have advance liver fibrosis $(27.6 \%)$ in comparison with non-IDUs $(5.6 \%, P=0.062)$.

\section{Discussion}

Addict populations, particularly IDUs, are among the groups with the highest prevalence of $\mathrm{HCV}$ infection in Iran, ${ }^{18}$ where the rates of anti-HCV seropositivity among the general population and blood donors were reported to be $0.4 \%$ and $0.1 \%$, respectively. ${ }^{5,19}$ Today, low-cost and high-quality generic versions of new direct-acting antiviral drugs for $\mathrm{HCV}$ treatment are available with insurance coverage in Iran. ${ }^{18}$ On the other hand, it was estimated that only one-third of the Iranian population with HCV infection in 2014 had been diagnosed. ${ }^{5}$ It seems that HCV elimination will be possible if broad case finding programs are carried out, particularly among difficult-to-reach highrisk groups such as drug users with risky behaviors in the country. Low-cost and less time-consuming rapid screening tests can be performed by less educated providers to detect anti-HCV with acceptable sensitivity and specificity.

Using RDTs, we detected a 30-fold higher rate of $\mathrm{HCV}$ prevalence among drug users living in drug treatment and harm reduction centers of Mashhad, Iran (12.8\%, 95\% CI: $9.6 \%-16.5 \%)$ as compared to the rate in the general population of this city $(0.42 \%, 95 \% \mathrm{CI} ; 0.17 \%-0.87 \%) .{ }^{14}$ Furthermore, we identified the highest prevalence of HCV infection (42.6\%, 95\% CI: 30.7\%-55.2\%) among substance abusers with a history of injection, with the highest odds in regression analysis (OR: 6.86).

The validity and reliability of RDTs were recently confirmed as an alternative for laboratory screening of anti-HCV in the prison setting in Iran. ${ }^{20}$ The authors reported both sensitivity and specificity at $100 \%$ for the RDTs when they excluded testing error in prison and considered PCR technique as the confirmatory method for active HCV replication. Moreover, the investigators reported the same performance of the test on both fingerstick and anti-coagulated blood specimens. The current 
survey presented our experience with HCV rapid testing in an out-of-prison setting in Iran.

Interestingly, our findings were consistent with the previously reported data from Mashhad as well as other cities of Iran. In a study in 2001, the seroprevalence of HCV among 101 IDUs incarcerated in the central prison of Mashhad was shown to be $59.4 \%$, but the rate among blood donors was found to be as low as $0.1 \%$ in that time. ${ }^{21}$ Likewise, in another survey in Mashhad, the risk of HCV infection among prisoners with a history of drug addiction was significantly higher than those without such a history (OR: 2.54, 95\% CI: 1.96-3.31). ${ }^{15}$ A systematic review estimated a national $\mathrm{HCV}$ prevalence of $6.2 \%$ (95\% CI: 3.4\%-9.6\%) for the Iranian populations at intermediate risk such as healthcare personnel, female sex workers, prisoners, homeless people, and non-IDUs, with a median of $14.5 \%$ for the last group. Besides, an overall prevalence of $32.1 \%$ (95\% CI: $28.1 \%-36.2 \%$ ) was estimated for high-risk populations comprising HIV-positive individuals, multi-transfused patients, and IDUs, with the highest prevalence $(52.2 \%$, 95\% CI: $46.9 \%-57.5 \%$ ) for subpopulations of IDUs. ${ }^{9}$. Similarly, a systematic review of 46 studies published between 2003 and 2016 reported an HCV prevalence of 32.3\% (95\% CI: 26\%-39\%) among high-risk Iranian populations including female sex workers, prisoners, drug-dependent individuals, and IDUs totally. The pooled prevalence was estimated at 16.2\% (95\% CI: $12.6 \%-20.1 \%$ ) and 41.3\% (95\% CI: 29.8\%-53.3\%) for the last two groups, respectively. ${ }^{10}$ Our estimation of $\mathrm{HCV}$ prevalence among IDUs in northeastern Iran (42.6\%) was also very close to the mean rate estimated for this population in countries of the Middle East and North Africa region (49.3\%). ${ }^{22}$

Sharing injecting equipment such as syringes, needles, and mixing containers among IDUs or inhalation tools among non-IDUs is associated with a higher risk of HCV infection. ${ }^{12,17}$ A systematic review showed that syringesharing Iranian IDUs were four times more likely than other IDUs to be at risk of HCV infection. ${ }^{8}$ There is also an increased risk of blood-to-blood transmission of viral hepatitis via contaminated equipment used for cosmetic procedures such as tattooing and body piercing. ${ }^{13} \mathrm{~A}$ more than 2.7-fold increased risk for HCV infection has been estimated for tattoo recipients; however, a stronger association between tattooing and risk of hepatitis $\mathrm{C}$ was found among non-IDUs (OR: 5.7, 95\% CI 2.0-16.7). ${ }^{23}$ Similarly, the prevalence of $\mathrm{HCV}$ infection among our IDU population with a history of sharing injection equipment $(51.7 \%)$ was higher than those who reported not sharing (9.6\%). Besides, the risk of HCV infection among substance abusers with a history of tattoos was significantly higher than those without such a history (OR: 2.64, 95\% CI: 1.16-6.01). Correspondingly, a systematic review estimated the higher pooled $\mathrm{HCV}$ prevalence among IDUs with a history of tattoos $(72 \%$,
95\% CI: 55-88\%) in comparison with those without this history (55\%, 95\% CI: 40-70\%). ${ }^{11}$

History of incarceration has been considered as another important risk factor among people who abuse substances. ${ }^{17}$ In the current study, the rate of HCV infection among the population with a history of imprisonment (18.0\%) was significantly higher than those without such a history $(4.2 \%)$, however, the risk was not significantly different in multivariate analysis (OR: 1.42, 95\% CI: 0.50-3.99). A recent systematic review reported a higher rate of $\mathrm{HCV}$ prevalence among drug-dependent prisoners $(24.6 \%, 95 \%$ CI: 36\%-58\%) compared to drug users with no history of detention (16.2\%, 95\% CI: 12.6\%-20.1\%). ${ }^{10}$ In another systematic review, the pooled rate of $\mathrm{HCV}$ infection was higher among IDUs with a history of imprisonment (58\%, 95\% CI: 39-77\%) versus those without this history (44\%, 95\% CI: 20-68\%). ${ }^{11}$ Additionally, in a systematic review of 42 studies published from 2000 to 2019, the rate of infection among incarcerated IDUs (52\%, 95\% CI: $38-67 \%)$ was higher than those without an incarceration history (45\%, 95\% CI: 36-54). ${ }^{8}$

Assessment of the degree of liver damage is required for making accurate decisions regarding treatment and management of HCV infection. ${ }^{18}$ Nevertheless, it would be impractical to use a liver biopsy or expensive noninvasive imaging methods in resource-limited settings. For our studied population, we applied some non-invasive laboratory-based tests for measurement of indirect markers of liver fibrosis which are accessible at any HCV infection management center. Based on APRI and FIB-4 scores, the likelihood of significant liver fibrosis was suggested for $14.3 \%$ and $18.4 \%$ of patients affected by HCV infection, respectively. Similarly, Mehta et al characterized $\mathrm{HCV}$ infection and its related liver disease prevalence among IDUs in Chennai, India, during 2005-2006. The frequency of anti-HCV among 1158 IDUs was $54.5 \%$; of a random sample of 400 anti-HCV seropositive cases tested for HCV RNA, 70.3\% had a positive result. Using APRI, the prevalence of significant liver fibrosis was $7.0 \%$ among 557 IDUs, 3.5\% among $317 \mathrm{HCV}$-negative persons, and $11.5 \%$ among $122 \mathrm{HCV}$-positive persons. ${ }^{24}$ Furthermore, the proportion of patients with advanced hepatic fibrosis (FIB-4 >325) was reported to be $0.5 \%, 1.3 \%, 4.6 \%$, and $8.6 \%$ among HIV/HCV-uninfected, HIV-monoinfected, $\mathrm{HCV}$-monoinfected, and HIV/HCV-coinfected women in the US, respectively. ${ }^{25}$ Consistently, the estimated prevalence of advanced liver fibrosis (FIB-4 > 3.25) was higher among HCV/HIV-coinfected patients (9.2\%) than $\mathrm{HCV}$-monoinfected patients (3\%, OR: 3.3). ${ }^{26}$ In that study, between 1994 and 2006, the estimated advanced hepatic fibrosis on admission in a substance abuse treatment center in Badalona, Spain, was associated with an increased risk of death (RR 3.9); mortality rates were similar in HCV-monoinfected (7.49) and HCV/HIVcoinfected patients (6.06). 
Our survey has some limitations. Due to executive difficulties, we selected the study locations based on a non-random sampling method which might restrict the generalization of our results to the target population. We also did not check probable false negative results; however, a high value of sensitivity (99.3\%) has been reported for the HCV RDT kits.

In conclusion, our experience showed that screening for HCV infection with a RDT would make it possible to identify populations with the infection in hard-to-reach settings such as substance treatment and harm reduction centers. Besides, assessment of liver fibrosis by noninvasive and low-cost lab tests would allow the physician to design an accurate plan for the management of $\mathrm{HCV}$ infection in poor populations.

\section{Authors' Contribution}

MRHM: Study concept and design, data collection, analysis, and interpretation, drafting and revision of the manuscript. HS: Data collection. MD: Study design, data collection, project coordination. SAV: Data collection. All authors have read and approved the final manuscript.

\section{Conflict of Interest Disclosures}

The authors declare that they have no conflicts of interest.

\section{Ethical Statement}

The Ethical Committee of ACECR, Razavi Khorasan Branch approved this study (Code: IR.ACECR.JDM.REC.1397.18).

\section{Acknowledgements}

This work was financially supported by the Research and Technology Deputy of Academic Center for Education, Culture \& Research (ACECR), Razavi Khorasan Branch, Mashhad, Iran. We would like to thank Dr. Gholamreza Shariat-Gonabadi, Ms. Ghorbani, Mr. Mostafa Azari and Mr. Javad Rafiee and their colleagues for their kind collaboration in the drug treatment centers of Mashhad, Iran. We also appreciate Dr. Ghodsi and his colleagues in the Central Lab of ACECR, Razavi Khorasan Branch, Mashhad, Iran, for their kind cooperation.

\section{References}

1. Blach S, Zeuzem S, Manns M, Altraif I, Duberg AS, Muljono $\mathrm{DH}$, et al. Global prevalence and genotype distribution of hepatitis C virus infection in 2015: a modelling study. Lancet Gastroenterol Hepatol. 2017;2(3):161-76. doi: 10.1016/ S2468-1253(16)30181-9.

2. World Health Organization. Hepatitis C. Available from: https://www.who.int/news-room/fact-sheets/detail/hepatitis-c. Accessed 27 July 2020.

3. Mirminachi B, Mohammadi Z, Merat S, Neishabouri A, Sharifi $\mathrm{AH}$, Alavian $\mathrm{SH}$, et al. Update on the prevalence of hepatitis $\mathrm{C}$ virus infection among Iranian general population: A systematic review and meta-analysis. Hepat Mon. 2017;17(2):e42291. doi: 10.5812/hepatmon.42291.

4. Alavian SM, Haghbin H. Relative importance of hepatitis B and $C$ viruses in hepatocellular carcinoma in EMRO countries and the Middle East: a systematic review. Hepat Mon. 2016;16(3):e35106. doi: 10.5812/hepatmon.35106.

5. Hajarizadeh B, Razavi-Shearer D, Merat S, Alavian SM, Malekzadeh R, Razavi H. Liver disease burden of hepatitis $C$ virus infection in Iran and the potential impact of various treatment strategies on the disease burden. Hepat Mon. 2016;16(7):e37234. doi: 10.5812/hepatmon.37234.

6. Zeldis JB, Jain S, Kuramoto IK, Richards C, Sazama K,
Samuels S, et al. Seroepidemiology of viral infections among intravenous drug users in northern California. West J Med. 1992;156(1):30-5.

7. Nelson PK, Mathers BM, Cowie B, Hagan H, Des Jarlais D, Horyniak D, et al. Global epidemiology of hepatitis B and hepatitis $C$ in people who inject drugs: results of systematic reviews. Lancet. 2011;378(9791):571-83. doi: 10.1016/ S0140-6736(11)61097-0.

8. Behzadifar M, Behzadifar M, Bragazzi NL. A systematic review and meta-analysis of the prevalence of hepatitis $C$ virus infection in people who inject drugs in Iran. BMC Public Health. 2020;20(1):62. doi: 10.1186/s12889-020-8175-1.

9. Mahmud S, Akbarzadeh V, Abu-Raddad LJ. The epidemiology of hepatitis C virus in Iran: systematic review and metaanalyses. Sci Rep. 2018;8(1):150. doi: 10.1038/s41598-01718296-9

10. Nematollahi S, Ayubi E, Almasi-Hashiani A, Mansori K, Moradi $Y$, Veisani $Y$, et al. Prevalence of hepatitis $C$ virus infection among high-risk groups in Iran: a systematic review and meta-analysis. Public Health. 2018;161:90-8. doi: 10.1016/j. puhe.2018.04.011

11. Malekinejad M, Navadeh S, Lotfizadeh A, Rahimi-Movaghar A, Amin-Esmaeili M, Noroozi A. High hepatitis C virus prevalence among drug users in Iran: systematic review and meta-analysis of epidemiological evidence (2001-2012). Int J Infect Dis. 2015;40:116-30. doi: 10.1016/j.ijid.2015.09.022.

12. World Health Organization. Global health sector strategy on viral hepatitis 2016-2021; Towards ending viral hepatitis. 2016. Available from: https://www.who.int/hepatitis/ strategy2016-2021/ghss-hep/en/.

13. World Health Organization. WHO guidelines on hepatitis B and C testing. 2017. Available from: https:// www.who.int/ hepatitis/publications/guidelines-hepatitis-c-b-testing/en.

14. Ahmadi Ghezeldasht S, Hedayati-Moghaddam MR, Shamsian K, Fathimoghadam F, Bidkhori HR, Rezaee SA. Prevalence of Hepatitis C Virus Infection in General Population of Mashhad, Northeastern Iran. Iran J Public Health. 2017;46(3):408-13.

15. Khajedaluee $M$, Babaei A, Vakili R, Valizade N, Homaei Shandiz F, Alavian SM, et al. Sero-Prevalence of Bloodborne Tumor Viruses (HCV, HBV, HTLV-I and KSHV Infections) and Related Risk Factors among Prisoners in Razavi Khorasan Province, Iran, in 2008. Hepat Mon. 2016;16(12):e31541. doi: 10.5812 /hepatmon.31541.

16. Iran's Islamic Parliament Research Center. Amendment of the Anti-Narcotics Law approved in 1997. 2010. (In Persian). Available from: https://rc.majlis.ir/fa/law/show/789916.

17. World Health Organization. WHO Guidelines for the screening care and treatment of persons with chronic hepatitis C infection. 2016. Available from: https://www.who.int/ hepatitis/publications/hepatitis-c-guidelines-2016/en.

18. Alavian SM, Hajarizadeh B, Bagheri Lankarani K, Sharafi H, Ebrahimi Daryani N, Merat S, et al. Recommendations for the Clinical Management of Hepatitis C in Iran: A ConsensusBased National Guideline. Hepat Mon. 2016;16(8):e40959. doi: 10.5812/hepatmon.guideline.

19. Mohammadali F, Pourfathollah AA. Changes in frequency of HBV, HCV, HIV and syphilis infections among blood donors in Tehran province 2005 - 2011. Arch Iran Med. 2014;17(9):61320.

20. Sharafi H, Poustchi H, Azimian F, Tamadoni B, Ramezani R, Gouya MM, et al. Performance of a rapid diagnostic test for screening of hepatitis $C$ in a real-life prison setting. J Clin Virol. 2019;113:20-3. doi: 10.1016/j.jcv.2019.02.005.

21. Rowhani Rahbar A, Rooholamini S, Khoshnood K. Prevalence of HIV infection and other blood-borne infections in incarcerated and non-incarcerated injection drug users (IDUs) in Mashhad, Iran. Int J Drug Policy. 2004;15(2):151-5. doi: 10.1016/j.drugpo.2003.07.001. 
22. Mahmud S, Mumtaz GR, Chemaitelly H, Al Kanaani Z, Kouyoumjian SP, Hermez JG, et al. The status of hepatitis C virus infection among people who inject drugs in the Middle East and North Africa. Addiction. 2020;115(7):1244-62. doi: 10.1111/add.14944.

23. Jafari S, Copes R, Baharlou S, Etminan M, Buxton J. Tattooing and the risk of transmission of hepatitis C: a systematic review and meta-analysis. Int J Infect Dis. 2010;14(11):e928-40. doi: 10.1016/j.ijid.2010.03.019.

24. Mehta SH, Vogt SL, Srikrishnan AK, Vasudevan CK, Murugavel KG, Saravanan S, et al. Epidemiology of hepatitis C virus infection \& liver disease among injection drug users (IDUs) in Chennai, India. Indian J Med Res. 2010;132:706-14.

25. Blackard JT, Welge JA, Taylor LE, Mayer KH, Klein RS, Celentano DD, et al. HIV mono-infection is associated with FIB-4 - A noninvasive index of liver fibrosis - in women. Clin Infect Dis. 2011;52(5):674-80. doi: 10.1093/cid/ciq199.

26. Sanvisens A, Fuster D, Serra I, Tor J, Tural C, Rey-Joly $\mathrm{C}$, et al. Estimated liver fibrosis and its impact on allcause mortality of HCV-monoinfected and HCV/HIVcoinfected drug users. Curr HIV Res. 2011;9(4):256-62. doi: 10.2174/157016211796320298.

(c) (i) (c) 2021 The Author(s). This is an open-access article distributed under the terms of the Creative Commons Attribution License (http://creativecommons. org/licenses/by/4.0), which permits unrestricted use, distribution, and reproduction in any medium, provided the original work is properly cited. 